\title{
O Sudeste Asiático entre Estados Unidos e China: "arquipélago de economias de mercado" ou palco da competição interestatal capitalista?
}

\section{Southeast Asia amidst the United States and China: "market economies archipelago" or inter-capitalist competition stage?}

DOI: $10.21530 /$ ci.v11n3.2016.489

Bruno Hendler ${ }^{1}$
Isabela Nogueira $^{2}$

\section{Resumo}

Este artigo examina a projeção da China sobre o Sudeste (SE) Asiático a partir de três ciclos recentes: 1990-1997, 1997-2008, e de 2008 até hoje. Tem-se como hipótese que o SE Asiático tem se tornado um palco de grande relevância no jogo de poder e riqueza entre EUA e China desde 2008, e se afastado do cenário proposto por Giovanni Arrighi e Beverly Silver de formação de um "arquipélago de economias de mercado", no qual as disputas por poder estariam subordinadas a ganhos coletivos por meio da interdependência econômica. Com foco na relação histórica SE Asiático-China, argumenta-se que, apesar do esforço diplomático desse país, o terceiro ciclo de relações com a região é mais agressivo e tem elevado as assimetrias nas esferas comercial, financeira e político-militar. Somando-se isso ao pivô estratégico da administração Obama, concluímos que o acirramento da disputa entre as potências é um cenário provável.

Palavras-Chave: Relações China-Sudeste Asiático; Arquipélago de Economias de Mercado; Competição Interestatal; Pivô Estratégico.

\footnotetext{
Abstract

The article analyses China's projection on Southeast (SE) Asia based on three recent cycles: 1990-1997, 1997-2008, and 2008 to date. Our hypothesis is that SE Asia has become an increasingly important stage in the game of power and wealth between the US and China ever

1 Doutorando do Programa de Pós-Graduação em Economia Política Internacional da Universidade Federal do Rio de Janeiro e pesquisador do LabChina (Laboratório de Estudos em Economia Política da China).

2 Professora Adjunta do Instituto de Economia e do Programa de Pós-Graduação em Economia Política Internacional da Universidade Federal do Rio de Janeiro e coordenadora do LabChina.

Artigo submetido em 14/06/2016 e aprovado em 03/11/2016.
} 
since 2008, moving away from the proposed scenario by Giovanni Arrighi and Beverly Silver of a "world market economy" in which power disputes would be subordinated to collective gains obtained through economic interdependence. Focusing on SE Asia-China historical relationship, we argue that despite the latter's diplomatic effort, the third cycle (from 2008 onwards) is more aggressive and generates higher asymmetries through trade, financial and political-military spheres. This process, coinciding with the strategic pivot of the Obama administration, tends to intensify the dispute between the great powers over the region.

Keywords: China-Southeast Asia Relations; Market Economies Archipelago; Inter-State Competition; Strategic Pivot.

\section{Introdução}

As mudanças tectônicas que a ascensão da China vem provocando no sistema-mundo estão, como era de se esperar, promovendo transformações estruturais na periferia asiática. Encravado entre o Subcontinente Indiano, o Nordeste Asiático e a Oceania, localizado entre as principais rotas navais do Pacífico e do Índico e berço de um dos principais blocos econômicos da atualidade, o Sudeste (SE) Asiático é um dos palcos principais das disputas internacionais por poder e riqueza da contemporaneidade. Juntos, os países da Associação das Nações do Sudeste Asiático (ASEAN) respondem por um PIB de US\$2,57 trilhões (dados de 2014) e têm de lidar com a benção/maldição da proximidade com a China - um mercado consumidor em expansão (principalmente de commodities e de produtos industriais de baixo valor agregado), mas também um concorrente de empresas nativas que buscam saltos na cadeia produtiva.

Na esfera geopolítica, o SE Asiático é, também, uma região extremamente dinâmica, pois a ausência de dilemas nucleares faz com que as esferas convencionais de poder militar e de diplomacia tenham margens ainda maiores de atuação e transformação. Mas a ausência de Estados nucleares significa maior vulnerabilidade às pressões sistêmicas das grandes potências - seja na Guerra Fria entre URSS e EUA, ou no pós-Guerra Fria entre China e EUA.

Diante disso, o presente artigo tem como hipótese a ocorrência de um novo e terceiro ciclo de interações do SE Asiático com as pressões sistêmicas no pósGuerra Fria. O primeiro, de 1989 a 1997, foi marcado pela normalização das relações bilaterais com a China e a gradual redução das forças de Washington, que, na ausência da URSS, buscava o isolamento de Pequim com base na ameaça geopolítica e nas violações dos Direitos Humanos em Tiananmen. O segundo, de 
1997 a 2008, caracterizou-se pela ofensiva multilateral chinesa, aderindo a normas e organizações regionais para reduzir a percepção de ameaça de sua "ascensão pacífica” e, acima de tudo, pelos empréstimos a juros baixos e valorização do renminbi como formas de resgate das economias do SE Asiático atingidas pela crise financeira de 1997. A atuação chinesa torna-se ainda mais decisiva nesse período diante do vácuo de poder deixado pelos norte-americanos, cujo foco na Guerra ao Terror deslocara boa parte das atenções de Washington para o Oriente Médio.

Por fim, o terceiro ciclo, ainda em andamento, é marcado por três processos: o "retorno" dos EUA à Ásia com o advento do pivô estratégico do governo Obama, uma nova política externa chinesa para o mundo e para a região, muito mais assertiva e propositiva, e o aprofundamento dos laços econômicos da China com o SE Asiático, acompanhado de uma dubiedade entre discurso e postura em relação aos litígios territoriais no Mar do Sul da China, especialmente com Vietnã e Filipinas. E é precisamente essa encruzilhada de projeções sistêmicas que corrobora nossa hipótese de que o SE Asiático se torna uma região mais distante de um “arquipélago de economias de mercado”, conforme sugerido por Giovanni Arrighi, e mais próxima do sistema interestatal capitalista pautado pela competição entre Estados e empresas.

Este artigo está dividido em seis partes além desta introdução. Na seção seguinte, apresentamos a tese de Arrighi e Silver de bifurcação das capacidades sistêmicas e da suposta constituição de um “arquipélago de economias de mercado" integrado na região, e na seção três fazemos uma breve revisão da história das relações da China com o Sudeste Asiático. A seção quatro está dedicada à análise das duas primeiras fases das relações econômicas e políticas no pós-Guerra Fria. E a seção cinco detalha a pressão competitiva e conflituosa e mais recente, sendo sucedida pelas considerações finais.

\section{Do “arquipélago de economias de mercado” à competição capitalista}

Em sua última obra de grande porte, Arrighi (2008, p. 22) defendia a tese de que o gradual desengajamento norte-americano da Ásia Oriental no contexto de auge do "atoleiro" militar do Iraque, em 2008, implicaria em um processo de integração econômica das nações asiáticas que teria a China como principal força motriz e ofuscaria as principais tensões geopolíticas da região em prol do desenvolvimento. Para o autor (2008, p. 308), não haveria razão para uma corrida 
armamentista na Ásia que beneficiaria, em última instância, a indústria bélica e a economia dos EUA e "solaparia a posição de credor que constitui a principal fonte do poder dos Estados asiáticos".

No contexto da Guerra do Iraque e da crise financeira nos EUA em 2008, bem como da aproximação (bilateral e multilateral) da China com seus vizinhos ao longo dos anos 1990 e 2000, a conformação de um "arquipélago de economias de mercado" menos preocupadas com dilemas de segurança na Ásia Oriental parecia uma possibilidade concreta. Mas o "retorno" dos EUA à Ásia Oriental com o pivô estratégico do governo Obama e a posição mais assertiva da China no tocante a questões de comércio, segurança e defesa recolocam a região no caminho "normal" da competição interestatal e capitalista que caracterizam o sistema-mundo moderno.

Para colocar essas transformações em perspectiva de longa duração, é preciso resgatar a tese de Arrighi (2008) e Arrighi e Silver $(2001,2011)$ sobre a bifurcação das capacidades sistêmicas. Para os autores, a atual crise hegemônica norte-americana, iniciada com a chamada "crise sinalizadora" dos anos 1970, concentrou ainda mais os recursos militares globais nas mãos do Ocidente (em especial, do próprio EUA) ao passo que deslocou os recursos financeiros globais para a Ásia Oriental (em especial para a China), que estaria rumando para a formação de um arquipélago de economias de mercado cujas unidades políticas, embora fortalecidas em relação ao Ocidente, seriam movidas pela busca de riqueza nas cadeias de mercadorias sob a hegemonia do regime militar norte-americano.

Arrighi e Silver (2011) estão corretos ao apontar a China como principal ator de reciclagem da liquidez mundial para o Sul Global (e para o Sudeste Asiático em particular) e como uma base manufatureira com cada vez maior capacidade de ditar elementos da dinâmica de acumulação de capital mundial. Porém, os cenários apontados a partir desse processo são incertos e deixam algumas lacunas. Para os autores, uma nova hegemonia (um Estado, uma coalização de Estados ou um Estado-mundo) teria que acomodar e promover uma maior igualdade entre o Norte e o Sul Global. Nossa crítica, entretanto, está na fraqueza do conceito de hegemonia utilizado nos ciclos sistêmicos de acumulação, que não prevê a possibilidade de fissão de capacidades sistêmicas, e aponta para o estabelecimento de um modelo híbrido, no qual o poder político-militar seria mantido no Ocidente e o poder econômico na Ásia.

Tal modelo híbrido, entretanto, é falacioso tanto na sua perspectiva política quanto econômica. Ainda que os EUA tenham aumentado suas capacidades 
militares globais, em termos regionais a China tem buscado firmar-se como um contrapeso geopolítico. China e Rússia também exercem pressões competitivas sobre a faixa do rimland da Eurásia (da Europa Oriental, passando pelo Oriente Médio, Cáucaso, Ásia Central e Ásia Oriental) que ameaçam os arranjos geopolíticos construídos pelos EUA durante e após a Guerra Fria. Isso significa dizer que a centralização das capacidades militares globais nas mãos dos EUA tem garantido cada vez menos retornos de poder quando dinâmicas regionais envolvendo Rússia e China estão em jogo.

Em segundo lugar, do ponto de vista do poder econômico, a suposta bifurcação também não se sustenta. Ainda que uma parte crescente e já crucial da acumulação de capital em escala global esteja se dando na China, as cadeias globais de valor e sua dimensão hierárquica continuam fazendo com que os detentores das grandes corporações (e das marcas) ocidentais continuem sendo aqueles que absorvem a maior parte da agregação de valor. Ainda que esteja havendo um processo contínuo de transformação estrutural e de subida da China nas cadeias globais, o país ainda está distante da capacidade das firmas norte-americanas de coordenação das cadeias e de absorção da massa de mais-valia assegurada justamente em função da elevada taxa de exploração da mão de obra chinesa.

De toda forma, o Sudeste Asiático aparece como um “laboratório de análise” dessa problemática precisamente porque se tornou uma região estratégica tanto do ponto de vista dos novos padrões de acumulação de capital em escala global, via sua inserção nas cadeias globais de valor que passam pela China, quanto por conta da dinâmica do poder regional fortemente afetada pela atuação dos EUA e da própria China. Dessa forma, ao cruzar fatores econômicos com político-estratégicos, pretende-se argumentar que, ao invés de um arquipélago de economias de mercado (no sentido smithiano) submetido à carapaça militar unilateral dos EUA, a Ásia Oriental (e uma sub-região específica, o Sudeste Asiático) já se tornou um palco privilegiado de disputas capitalistas (no sentido braudeliano) e interestatais com o protagonismo tanto de EUA e quanto da China.

\section{Breve história da relação China-Sudeste Asiático}

Na condição de um dos principais territórios tributários da China imperial, o SE Asiático tem um histórico milenar de relações com o que chamamos de China moderna. Spence (2000, p. 129-130) narra que, em contraste com as relações 
conflituosas com os mongóis, zunghars e russos ao norte, ou com as relações de desconfiança com os missionários europeus, as relações com países como Vietnã, Tailândia e a antiga Birmânia eram administradas pelo Ministério dos Rituais, com enorme poder simbólico e peso dos costumes. Isso só era possível porque esses países compartilhavam, em algum grau, da prática do confucionismo e do budismo, de algum tipo de organização burocrática similar e de muitos dos valores básicos da cultura chinesa. Sob essa perspectiva, a lógica constitutiva do poder imperial chinês, muito menos expansionista se comparada à dinâmica europeia e muito mais ancorada na manutenção de um sistema construído ao redor de uma economia política agrária, fez com que a diplomacia com os povos fronteiriços ao sul fosse vista como mais um aspecto da tarefa de gerenciar "a grande harmonia" que metafisicamente cabia ao imperador chinês. Isso permitiu o estabelecimento de um sistema baseado em poucos gastos militares e extensivo uso de rituais, mas igualmente abundante na manipulação das forças rivais do SE Asiático, o que na prática promovia uma periferia dividida, mas não completamente caótica ou materialmente desprovida (AGLIETTA; BAI, 2013; SPENCE, 2000).

Embora a corrente historiográfica que enfatiza a harmonia nas relações da China com o SE Asiático seja coerente e bem fundamentada, arriscamo-nos a propor uma interpretação distinta. A formação e a expansão do Estado chinês a partir das dinastias clássicas (Qin e Han, entre os séculos III a.C. e III d.C.) foi concebida a partir de duas noções diferentes de “fronteira”. De um lado, os limites territoriais ao norte, defensivos e militarizados para conter as sucessivas agressões dos povos nômades das estepes, reforçam a tese da natureza autocentrada, pacifista e não expansionista do Estado chinês. Nessa região, devido a elementos geográficos e sociológicos, a fronteira da China permaneceu muito semelhante à atual.

De outro lado, a tese do caráter não expansionista do Estado chinês chocase com o processo milenar de expansão das fronteiras do império na direção sul, chegando até o atual norte do Vietnã na dinastia Tang (618-907). Embora a expansão também tenha ocorrido para o oeste em função da rota da seda, é no processo de incorporação de terras ao sul do Yangtzé, com o adensamento demográfico da etnia Han, melhoramento das técnicas agrícolas para o cultivo do arroz, incentivo ao comércio marítimo e difusão dos valores confucianos, que a China adquire o contorno territorial semelhante ao atual. Nesse sentido, a "fronteira sul” chinesa muito se assemelhou à “fronteira oeste” dos Estados Unidos no século XIX: uma verdadeira plataforma de difusão dos valores, instituições e população do núcleo civilizacional (a costa leste para os EUA e a planície em torno de Pequim para a 
China) sobre sociedades com instituições e estratificações sociais menos complexas e regiões repletas de riquezas naturais. A inexistência de uma "grande muralha" no sul do país é uma pequena ilustração do caráter "móvel" da fronteira nessa direção. E embora o Vietnã tenha se tornado o grande freio ao expansionismo chinês desde sua independência no século X, o Império do Meio protagonizou inúmeras investidas militares, principalmente sobre o SE Asiático continental (Vietnã e pequenos reinos da região de Burma, Laos e Tailândia), mas também insular (Java e Formosa) (STUART-FOX, 2003).

Com isso, argumentamos que além da simples influência comercial e civilizacional da China sobre o SE Asiático, um terceiro elemento precisa ser levado em conta: a esfera militar. É claro que incursões militares como as levadas à cabo pela China imperial são altamente improváveis atualmente, mas a concepção geopolítica de que a projeção sobre o "ventre mole" do SE Asiático é um caminho possível, faz parte do cálculo das lideranças chinesas. Tal como os EUA projetouse sobre a América Central com uma renovada narrativa expansionista após "fechar" suas fronteiras do oeste selvagem, a China pode fazer o mesmo sobre o SE Asiático. Assim, Robert Kaplan (2014) afirma que a China tem atuado como um "Estado westfaliano agressivo e inseguro" nos litígios territoriais do Mar do Sul da China, mas se olharmos para a história das longas durações, perceberemos que a China tem apenas lançado mão de mais um de seus artifícios de núcleo do sistema sinocêntrico tradicional. Em outras palavras, a obsessão chinesa pelo controle dos conjuntos de ilhotas na região pode ser interpretada como a expansão de um Estado westfaliano agressivo e inseguro ou como a mais recente versão de uma concepção geopolítica milenar que encara as fronteiras meridionais (antes terrestres e agora marítimas) como uma extensão "natural" da influência chinesa.

Em suma, a relação China-SE Asiático é historicamente hierárquica e desproporcional. Ela opunha, de um lado, o vasto território chinês, continental e unificado, de clima temperado e berço de uma importante capacidade de geração de excedente agrícola, a uma região de clima tropical, composta por uma mescla de arquipélagos e porções continentais irregulares habitados por povos que, em geral, não atingiram o grau de complexidade e organização social da China devido, essencialmente, à menor capacidade de geração de excedente agrícola e de consolidação de um Estado unificado. Em se tratando de um mundo préindustrial, a explicação do excedente produtivo como causa da assimetria de poder, riqueza e prestígio entre a China e os povos do SE Asiático faz sentido, vide, por exemplo, as obras de Janet Abu-Lughod (1989), Andre Gunder Frank 
(1998) e Jared Diamond (2006). Ademais, justifica a existência, por séculos, do chamado "sistema comercial-tributário", em que as nações desta região prestavam deferência ao imperador da China em troca do direito de fazer negócios e de promover missões comerciais periódicas com o Império do Meio.

Com a fundação da República Popular da China (RPC) em 1949 e o processo de descolonização da Ásia nas décadas seguintes, a relação desse país com o SE Asiático adquiriu novos contornos. No contexto de autoafirmação da RPC e de consolidação da soberania dos Estados do SE Asiático em plena Guerra Fria, nada era tão improvável quanto o ressurgimento do sistema comercial-tributário. Isso porque a percepção de ameaças era mútua: a China de Mao, isolada das grandes potências, via os países recém-independentes do SE Asiático caírem sob a esfera de influência tanto da URSS (Vietnã) quanto dos EUA (Tailândia, Filipinas, Indonésia, Malásia e Cingapura), gerando uma sensação de duplo cerco. Por outro lado, o discurso revolucionário de Mao e o apoio material e ideológico às diásporas chinesas (principalmente aquelas vinculadas a partidos comunistas) fez com que muitos desses países rompessem relações com a RPC e tivessem na China comunista a principal ameaça às suas soberanias.

A abertura econômica chinesa, em fins dos anos 1970, e o reatamento de relações comerciais com os países do SE Asiático, nos anos 1980, foram o prelúdio para o processo de normalização das relações diplomáticas com a região, nos anos 1990 - inclusive com o Vietnã, que travara uma guerra de fronteira com a China em 1978. A partir de então, a política externa chinesa para seus vizinhos do SE Asiático passou da desconfiança para a aproximação e a cooperação pragmática, ainda que desentendimentos continuassem latentes.

\section{A política externa da China para o SE Asiático: da normalização das relações bilaterais à charm offensive}

Dois momentos moldaram a percepção da China sobre o SE Asiático, aproximando-a dessa região. O primeiro, em 1989, foi o contexto da dissolução da União Soviética e da crise política em Tiananmen. Com o fim da Guerra Fria, a China perdeu parte do poder de barganha junto aos EUA e tornou-se o alvo principal das críticas e sanções do Ocidente por violações de direitos humanos, uma vez que a contenção da URSS não era mais necessária. Porém, ao contrário dos ocidentais, os países asiáticos optaram por um tom moderado e reagiram a 
Tiananmen como uma “questão interna” chinesa. Até o Japão, que endossara as sanções, retirou-se da coalizão ocidental antichinesa no ano seguinte (LI, 2009, p. 28). Assim, pela afinidade ao princípio da não intervenção em assuntos internos e pelo pragmatismo de romper com o isolamento ocidental, a China buscou, no começo dos anos 1990, a normalização das relações diplomáticas com boa parte dos países do SE Asiático.

Somados ao contexto de integração regional na América do Norte e na Europa, esses acontecimentos nutriram nas lideranças chinesas a percepção de que cooperação e integração regional seriam um caminho fundamental para a estabilidade e o desenvolvimento. Assim, o segundo momento veio ao final dos anos 1990. Em essência, as lideranças chinesas perceberam que uma abordagem multilateral em torno da ASEAN poderia diminuir a percepção de ameaça dos vizinhos em relação à “ascensão chinesa”, além de contrabalancear a presença norte-americana na Ásia (LI, 2009, p. 29). Até o final dos anos 1990, os Estados Unidos conseguiram ditar boa parte da institucionalização da dinâmica regional via seu controle na APEC (Asia-Pacific Economic Cooperation). Nesse sentido, a ASEAN e seus vários desdobramentos representavam a possibilidade de consolidação de um regionalismo com menor interferência norte-americana. É nesse momento que a China passa a adotar o que muitos especialistas denominaram de charm offensive (ACHARYA, 2008, p. 4), interpretando-o como o próprio uso do soft power enquanto políticas que deixam de lado o uso da força em prol de uma postura de diálogo, negociação e cooptação.

Essa charm offensive foi operacionalizada em diversas frentes. No âmbito econômico, a China solidarizou-se aos impactos da crise financeira de 1997, que atingiu em cheio muitas nações do SE Asiático. Ao contrário do FMI, o país forneceu pacotes de auxílio financeiro sem exigir contrapartidas políticas ou condicionalidades econômicas, além de resistir à desvalorização de sua moeda para incentivar as exportações dos países da região (ACHARYA, 2008, p. 3; KHAN, 2012, p. 98). A China também participou ativamente da criação da Iniciativa Chiang Mai, um mecanismo multilateral de swap que busca proteger os países asiáticos em caso de ataques especulativos. Buscou-se não apenas trocar informações sobre fluxos de capitais e monitorar possíveis abalos financeiros, mas estabelecer arranjos regionais que complementassem os instrumentos multilaterais existentes e evitassem novos choques sistêmicos. Como as trocas envolvem potencialmente as reservas chinesas, as pressões especulativas regionais estariam, em tese, minimizadas. Em conjunto, esses esforços visam evitar novas ingerências do FMI, 
do Banco Mundial e das potências Ocidentais nas economias asiáticas, buscando na cooperação regional alguma fonte de autonomia em relação às interferências dos organismos multilaterais (NOGUEIRA, 2008).

É também nesse momento que o país se consolida como o duplo polo na economia mundial (MEDEIROS, 2008, p. 256), com altíssimos déficits comerciais com o Sul Global (inclusive com o SE Asiático) e superávits comerciais ainda maiores com os países desenvolvidos. Isto é, enquanto as exportações chinesas cresciam em direção à tríade desenvolvida (EUA, UE e Japão), esses superávits eram "transmitidos" aos países semiperiféricos e periféricos do Sudeste e Leste da Ásia via integração produtiva vertical. Segundo Mu e Siam-Heng (2011, p. 131):

Para recuperar sua competitividade, as economias da ASEAN alavancaram o novo papel da China alinhando-se mais de perto com a fase de processamento da produção da China. Isto é ilustrado pelas alterações das exportações da ASEAN para a China a partir do final dos anos 1990. Ao invés de bens manufaturados, os produtos intermediários e matérias-primas tornaramse a maior parcela das exportações da ASEAN para a China. Este acordo económico entre a China e a ASEAN complementou a estratégia orientada para a exportação de ambos os lados ${ }^{3}$

Ainda no contexto de resgate das economias vizinhas após a crise de 1997, a China propôs um programa chamado Early Harvest, que derrubava as tarifas chinesas para produtos agrícolas oriundos da ASEAN. De fato, quando o projeto entrou em vigor, muitos dos países do SE Asiático foram beneficiados com o acesso privilegiado ao mercado chinês e apresentaram alto crescimento. E é precisamente o déficit comercial com os vizinhos da Ásia que passou a ser utilizado pela China como argumento para a integração regional e para a "boa vizinhança" em um jogo de soma positiva, em que todos sairiam ganhando.

No tocante à diplomacia multilateral, quatro temores persistiam: a) o possível predomínio da agenda dos EUA; b) a internacionalização da disputa pelas Ilhas Spratly; c) a inclusão da questão de Taiwan (como um assunto regional e não de foro interno chinês); e d) as possíveis exigências de transparência militar (LI, 2009, p. 30). Apesar desses temores, a China iniciou uma ofensiva multilateral,

3 To regain their competitiveness, ASEAN economies leveraged China's newfound role by aligning themselves more closely with the processing phase of China's production. This is illustrated by ASEAN's changes to its exports to China from the late 1990s onwards. Instead of manufacturing goods, intermediate products and raw materials became the primary composition of ASEAN's exports to China. This economic arrangement between China and ASEAN complemented the export-oriented strategy of both sides. (MU, SIAM-HENG, 2011, p. 131) 
assegurando-se que o ASEAN way, ou seja, a tomada de decisão gradual e por consenso, prevaleceria: em 1994, a China participou do ASEAN Regional Forum (ARF) pela primeira vez; em 1997, foi cofundadora do ASEAN + 3; em 2002, assinou quatro acordos com o ASEAN, incluindo a Declaração de Conduta das Partes no Mar do Sul da China; e em 2005, aderiu ao Tratado de Amizade e Cooperação da ASEAN, obtendo o direito de participar do East Asia Summit (NATHAN, SCOBELL, 2012). Na esteira dessa aproximação, o acordo de livre comércio entre China e ASEAN (CAFTA) entrou em vigor em 2010 e seus impactos já podem ser sentidos.

Apesar da ofensiva multilateral, a diplomacia bilateral não foi enfraquecida. A maior parte dos litígios de fronteiras terrestres foi resolvida (especialmente com Laos e Vietnã), exercícios militares conjuntos com Tailândia e Cingapura tiveram lugar, a cooperação com os países da Bacia do Rio Mekong se fortaleceu e o SE Asiático passou a receber visitas sucessivas de diplomatas, acadêmicos e militares chineses. Ademais, o país prestou relevante serviço humanitário no combate à SARS, em 2003, e na reparação da devastação causada pelo tsunami de 2004, fortalecendo ainda mais a charm offensive.

\section{O terceiro ciclo pós-Guerra Fria: o “retorno” dos EUA e a projeção da China}

Assumindo as rédeas do país em meio à crise financeira de 2008, Barack Obama não tardou em alterar os rumos da política externa dos EUA. Uma das principais guinadas foi o chamado "pivô estratégico" para a Ásia e o uso contínuo do termo "Ásia-Pacífico” ao invés de “Ásia Oriental”, dando a entender que os norte-americanos, assim como os chineses, fazem parte da mesma "Bacia do Pacífico” e, portanto, têm interesses legítimos na região.

No tocante ao SE Asiático, o pivô estratégico surge como uma iniciativa mais complexa do que a levada a cabo por George W. Bush nos anos anteriores, a qual foi pouco atuante nas esferas diplomática e econômica e pautou-se, majoritariamente, pela cooperação militar e de inteligência no âmbito da Guerra ao Terror. Percebendo a crescente relevância da Ásia-Pacífico, Obama tratou de deslocar o foco de sua política externa do Oriente Médio, com a retirada de tropas do Iraque e do Afeganistão, para aquela região, canalizando esforços militares, diplomáticos e econômicos. E embora Japão, Coreia do Sul e Taiwan atraíssem 
mais a atenção de Washington, o SE Asiático também ganhou importância, principalmente pelos efeitos da ascensão chinesa.

A ofensiva diplomática multilateral começou em 2009, quando Obama tornouse o primeiro presidente norte-americano a encontrar-se oficialmente com os dez membros da ASEAN, no que viria a ser chamado, em 2013, de US-ASEAN Summit. Em 2010, foi criada a missão permanente dos EUA para a ASEAN e, já no segundo encontro com o bloco, as partes emitiram uma nota em defesa da "livre navegação do Mar do Sul da China”, em nítida referência à projeção da marinha chinesa na região (KHAN, 2012, p. 102). Por fim, seguindo a linha do engajamento com o SE Asiático, a diplomacia dos EUA tem atuado ativamente em diversos foros, como o Asean Regional Forum, o East Asia Summit, o diálogo entre ministros de Defesa e o combate a crimes transnacionais e cibernéticos.

Embora o pivô estratégico tente apresentar-se como um instrumento diplomático, sua execução não pode ser dissociada da esfera militar (MAJID, 2013, p. 27). Assim, tanto aliados de longa data, como as Filipinas, quanto antigos rivais, como o Vietnã, têm recebido atenção especial dos EUA, seja com a reativação de bases militares (Filipinas) ou com a execução de exercícios militares conjuntos (Indonésia, Vietnã, Tailândia, Cingapura). No entanto, o confuso processo decisório nos EUA e a existência de agendas de segurança mais urgentes lançam dúvidas sobre o compromisso norte-americano em proteger seus aliados asiáticos em caso de possíveis agressões chinesas.

O chamado pivô estratégico também está intrinsicamente atrelado à economic statecraft dos EUA. Embora tenha acordos bilaterais de comércio com países da região, a criação do Transpacific Partnership (TPP), com a inclusão de Malásia, Brunei, Cingapura e Vietnã, é a mais recente materialização da estratégia norteamericana para responder ao desafio competitivo e geopolítico da China via acordos megarregionais. O TPP busca forjar um novo arcabouço institucional e regulatório, tentando imprimir o direcionamento estratégico dos EUA à remodelação do regime global de acordos internacionais de investimentos. E tenta, assim, contrapor-se à expansão econômica e política da China e assegurar a capacidade norte-americana, que vem desde o fim da Segunda Guerra, de ditar regras no Pacífico. Os próprios documentos do governo sobre o TPP explicitam a disposição norte-americana de exercer a liderança na Ásia, buscando evitar a predominância do que eles chamam de "modelos menos abertos" e que "não compartilham dos nossos interesses ou valores": 
As regras do caminho estão em jogo na Ásia (...). Se não aprovarmos este acordo e escrevermos essas regras, nossos concorrentes estabelecerão regras fracas, ameaçando empregos e trabalhadores americanos e minando a liderança dos EUA na Ásia (...). Para enfrentar esse desafio, os Estados Unidos devem desempenhar um papel de liderança na elaboração de regras de estrada que fortaleçam nossa economia e promovam um sistema econômico global justo. O TPP é como fazemos isso (...). E se não liderarmos no comércio, outros que não compartilham nossos interesses ou valores preencherão este vácuo (UNITED STATES TRADE REPRESENTATIVE, 2015, p. 1-2).4

Para além do comércio, o TPP inova ao propor um arcabouço regulatório e institucional que é, abertamente, contrário ao modelo de desenvolvimento chinês e que tem o potencial de constranger a expansão dos investimentos chineses na região. O acordo limita a possibilidade de utilização de instrumentos de política industrial largamente empregados na China nas últimas três décadas (como transferência de tecnologia e compras públicas), mina alguns dos pilares da internacionalização de empresas chinesas (sobretudo de empresas estatais) e estimula o uso de instrumentos de solução de conflitos como o Investor-State Dispute Settlement (ISDS), que colocam empresas transnacionais acima das leis de Estados nacionais soberanos (CARNEIRO, 2014; GEORGE, 2015).

O segundo processo em questão é a transição da liderança de Hu Jintao para Xi Jinping e a marcada mudança na política externa chinesa, que trocou seu lema da “ascensão pacífica” para o “sonho chinês” (zhongguo meng, 中国梦). Desde que Xi assumiu o poder, a política externa chinesa tornou-se muito mais assertiva e nacionalista, migrando de um padrão que buscava evitar chamar atenção para um padrão de busca por resultados (fen fa you wei, 奋发有为). A defesa geral é por uma política externa "mais ativa”, que garanta que os interesses chineses sejam expressados durante o processo de influenciar a ordem internacional (SØRENSEN, 2015). O novo lema do sonho chinês condensa uma série de conquistas nacionais e internacionais necessárias para o "grande rejuvenescimento nacional”, e implica sobretudo transformar a China em uma nação rica e forte em 2049, quando a RPC deve completar 100 anos, o que inclui projeção internacional de poder econômico,

4 "The rules of the road are up for grabs in Asia (...). If we don't pass this agreement and write those rules, our competitors will set weak rules of the road, threatening American jobs and workers and undermining U.S. leadership in Asia (...). To meet this challenge, the United States must play a leadership role in writing rules of the road that strengthen our economy and promote a fair global economic system. TPP is how we do that (...) And if we don't lead on trade, others who don't share our interests or values will fill the void. (UNITED STATES TRADE REPRESENTATIVE, 2015, pp. 1-2) 
político, cultural e militar. No final da década de 2000, Kissinger (2011, p. 484) já havia captado essa transição ao enfatizar o impacto dentro da China do lançamento de uma obra nacionalista que apresenta como grande meta nacional desbancar os EUA e tornar a China "o número um do mundo". O livro China Dream: the Great Power Thinking and Strategic Posture in the Post-American Era, do coronel Liu Mingfu, tornou-se um best-seller na China após seu lançamento, em 2009, e uma referência para o nacionalismo moderno chinês.

Tal assertividade da política externa chinesa já começa a se materializar em projetos ambiciosos, e a centralidade da Ásia e, especificamente, do SE Asiático, é marcada. O primeiro grande símbolo de uma política externa assertiva é o Banco de Infraestrutura e Investimento da Ásia (AIIB na sigla em inglês), criado em meados de 2015 com mais de 50 países membros e com a ruidosa exceção de EUA e Japão, que se opuseram ao projeto. O AIIB quer financiar a expansão dos investimentos chineses na região, sobretudo para ampliar a capacidade produtiva e a conectividade regional. E vai oferecer alternativas de investimento às construtoras e ao capital chinês, já saturados com um mercado interno que sofre com o excesso de capacidade em aço e equipamento pesado, e que tenta fazer a transição para um padrão de acumulação menos centrado no investimento e mais centrado no consumo (BATSON, 2015; MILLER, 2015).

Outro grande símbolo da política externa assertiva para a região é a nova rota da seda, que pretende reestabelecer as antigas rotas terrestres e marítimas da China. Trata-se de um conjunto ambicioso de portos, ferrovias, rodovias, grandes unidades de geração de energia e planos de urbanização ao longo de rotas que são comercial e estrategicamente relevantes para o entorno chinês. O SE Asiático, assim como a Ásia Central, são os pilares da nova rota. Além de obedecer à mesma lógica do AIIB de geração de demanda efetiva para as exportações e para os investidores chineses fora do país, a rota da seda marítima em torno do SE Asiático tem, claramente, objetivos geopolíticos. Ela busca facilitar a influência chinesa sobre o Mar do Sul da China, além de criar alternativas e controle indireto sobre rotas já bastante utilizadas e geopoliticamente vulneráveis para os chineses, como o estreito de Malaca, por onde passa cerca de $50 \%$ do comércio marítimo mundial.

A resposta dos países do SE Asiático à assertividade chinesa nas esferas comercial, financeira e político-militar tem sido um misto de desconfiança com tentativas de aproveitamento da onda de liquidez aberta. Conforme essas nações começam a gestar percepções mais claras da China enquanto ameaça e não apenas 
oportunidade, tornam-se plataformas para o "retorno" dos EUA para a Ásia e colocam a hipótese de Arrighi cada vez mais distante da realidade. A maior parte dos países do SE Asiático parece operar de maneira dual, engajando-se tanto com os acordos propostos pela China quanto, ao mesmo tempo, aproximando-se dos EUA, conforme sua nova agenda para a Ásia se torna mais explícita.

O terceiro grande processo que caracteriza esse mais recente ciclo é marcado por uma série de contradições (e tensões) comerciais e militares. O comércio entre a China e os países da ASEAN foi fundamental para a integração econômica da Ásia Oriental e para o desenvolvimento da região, um processo que ficou conhecido como uma segunda geração de "voo dos gansos". A relação China-ASEAN havia se figurado como o estado das artes das cadeias de valor globais, com os países do Sudeste fornecendo partes, peças, componentes e matérias-primas para bens montados e consolidados na China continental. Não por acaso, havia se formado, a partir dos anos 1990, um jogo de soma positiva, em que o SE Asiático obtinha expressivo superávit comercial com a China pela exportação de produtos de baixo valor agregado e essa, por sua vez, operava como um duplo polo, ao exportar produtos manufaturados para os países centrais. A reação chinesa à crise asiática de 1997 apenas acentuou tal processo, com o esforço para impedir a desvalorização do renminbi e assim preservar as exportações de seus vizinhos.

Mas com a entrada em vigor do China-ASEAN Free Trade Agreement (CAFTA) ${ }^{5}$ em 2010, com o desaquecimento do modelo chinês puxado pelos investimentos, com a persistente crise de demanda nos países centrais e com a queda nos preços internacionais das commodities, a assimetria entre as economias tornou-se evidente e o saldo dos fluxos comerciais se inverteu. Conforme mostra o gráfico abaixo, o saldo comercial da China com a ASEAN mudou bruscamente após 2012, rompendo com o padrão histórico de déficit chinês. Tal processo sugere a importância de mercados regionais periféricos para diversificar a dependência chinesa da demanda dos países centrais, notadamente dos EUA e da Europa (LI, 2009, p. 20). E evidencia o desafio competitivo que a indústria chinesa representa para a periferia asiática, sobretudo quando começa a se afastar da posição de "chão de fábrica" das manufaturas globais para se tornar também promotora de uma indústria com marcas próprias e mais agregação de valor em toda cadeia.

5 O CAFTA passou a valer, em 2010, para a China e os seis membros fundadores da ASEAN: Tailândia, Indonésia, Malásia, Filipinas, Brunei e Cingapura. Para os demais membros da ASEAN (Vietnã, Laos, Camboja e Mianmar), o acordo passaria a valer em 2015. 


\section{Gráfico 1. Saldo Comercial da China com a ASEAN}

(US\$ bilhão)

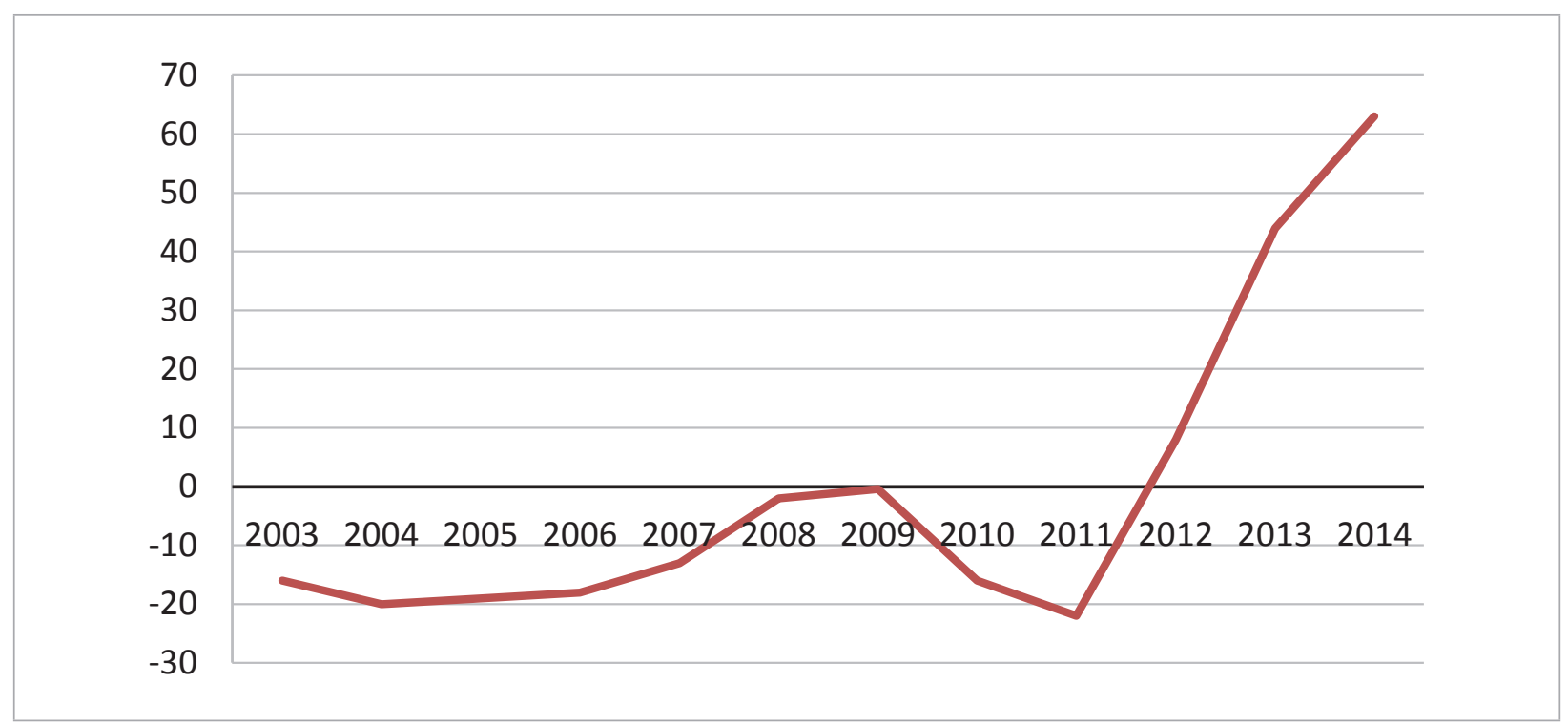

Fonte: Trade Map, 2016.

O gráfico abaixo apresenta a participação de China e EUA nas importações da ASEAN e, novamente, a virada da última década marca o início do salto chinês. Um breve exame qualitativo desse processo aponta para um aumento expressivo de produtos de maior valor agregado, principalmente celulares e computadores. Por outro lado, a pauta de exportações da ASEAN para a China está em fase de reprimarização, com a redução de manufaturados e a elevação de matérias-primas e produtos básicos.

Gráfico 2. Participações de EUA e China nas importações da ASEAN

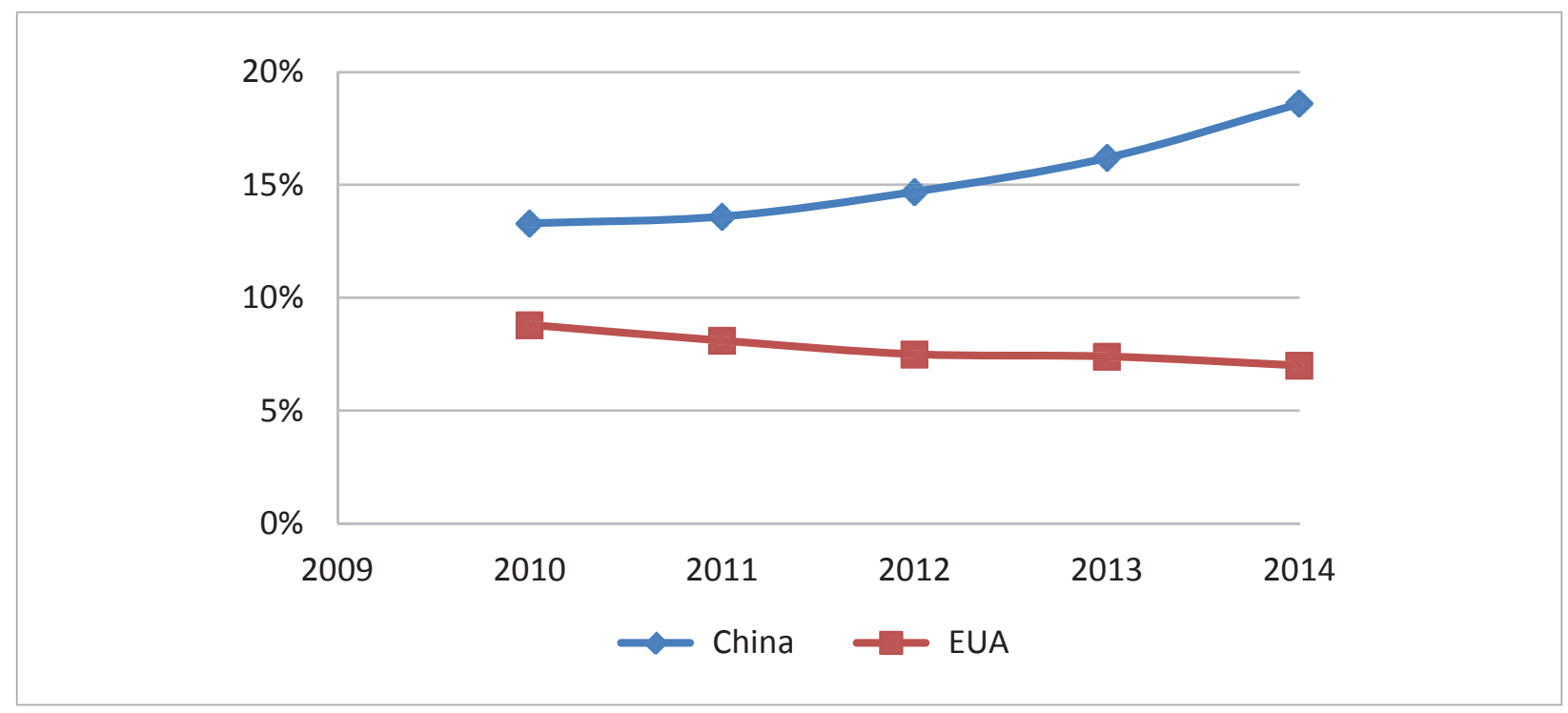


Os impactos de longo prazo do CAFTA ainda são pouco conhecidos, mas a inversão do saldo comercial em favor da China é um indício de que o país persegue em sua vizinhança uma periferia de mercados consumidores, para além da já estabelecida rede de fornecedores de matérias-primas. Se tal é a tendência de longo prazo, é algo a ser analisado em futuras pesquisas, já que os formuladores de política externa chinesa também tendem a se mostrar minimamente alertas à crise internacional e ao desequilíbrio que a reprimarização das exportações causa na periferia. Ademais, essa tendência precisa ser analisada sob o prisma da transição do modelo de desenvolvimento chinês, baseado em investimentos e exportações, para um modelo ainda em construção, voltado para a elevação da renda dos trabalhadores e para a expansão do mercado consumidor interno e regional.

Nesse sentido, conforme a China galga degraus na cadeia produtiva e expande seu mercado interno, começa a criar uma periferia econômica em seu entorno regional que, embora tenha um poder aquisitivo muito abaixo dos países desenvolvidos, contribui para reduzir a dependência chinesa de mercados no Ocidente. E esse fenômeno é ainda mais impactante quando visto em termos absolutos a partir da perspectiva da ASEAN (gráfico abaixo).

\section{Gráfico 3. ASEAN: principais parceiros comerciais}

(2014, em US\$ milhões)

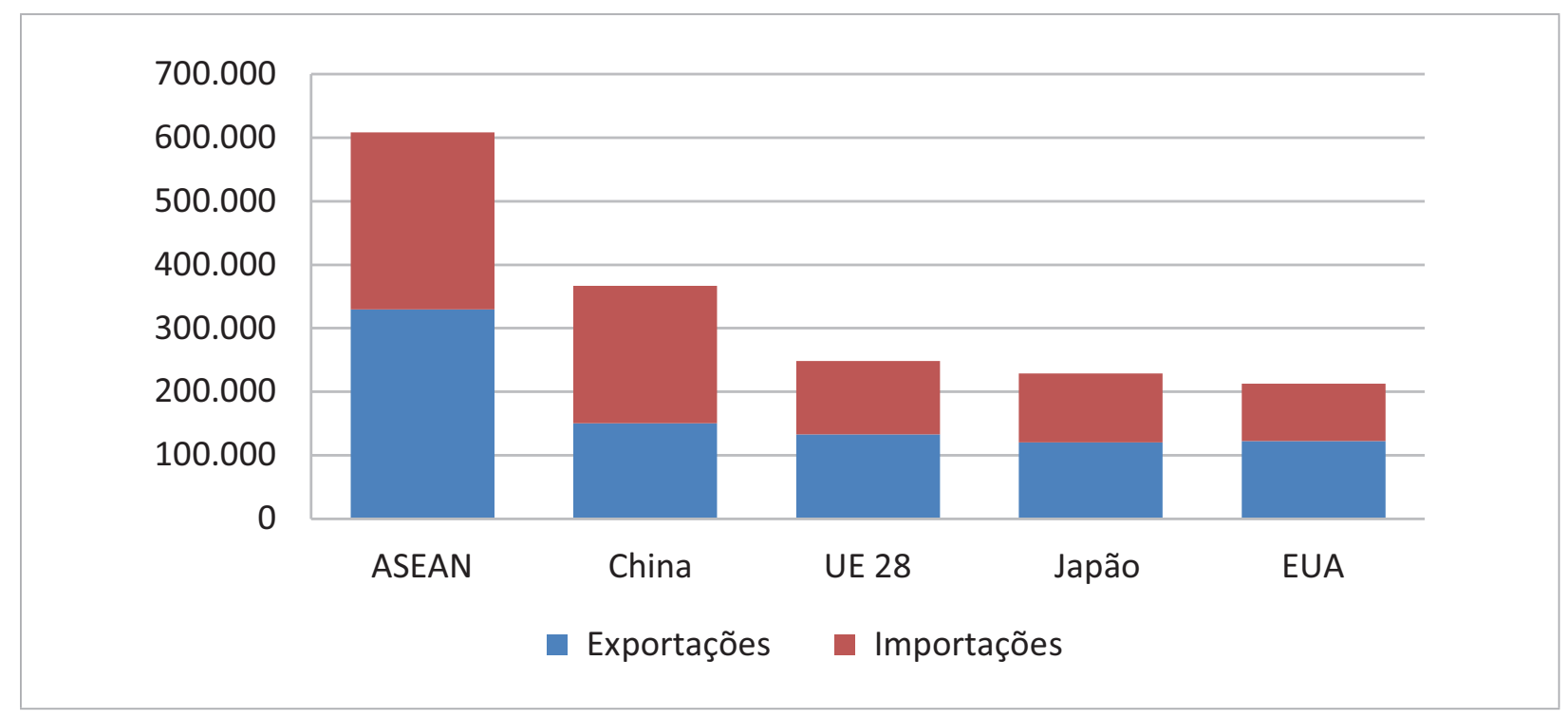

Fonte: ASEAN, 2016.

A crise de 2008 e seus impactos nos mercados ocidentais provocaram reflexões sobre o modelo de desenvolvimento que fez a "fortuna" da Ásia Oriental desde 
os anos 1960 e que depende da demanda efetiva dos Estados Unidos e da Europa para se materializar. Na mesma linha, as cadeias produtivas estabelecidas na região devem passar por um processo de redefinição, buscando a partir de agora incentivar cada vez mais o fortalecimento de mercados domésticos na China e no SE Asiático.

O apetite dos consumidores ocidentais levou ao colapso da demanda por bens fabricados a partir de componentes e matérias-primas de países asiáticos, africanos e latino-americanos e montados na China. Diante dessa mudança na ordem mundial, é necessário que a China e a ASEAN revisem seu papel na economia global para assegurar a continuidade de seu desenvolvimento econômico (MU, SIAM-HENG, 2011, p. 132). ${ }^{6}$

Além de comércio, também tem crescido o volume de investimentos estrangeiros diretos da China na ASEAN, muito embora EUA, Japão, União Europeia e o investimento intrabloco continuem muito superiores (gráfico 4). A criação do Banco de Infraestrutura e Investimento da Ásia (AIIB), com sede em Pequim, deve contribuir para mudar tal quadro, tornando-se uma das principais ferramentas de investimentos da China no SE Asiático nos próximos anos.

\section{Gráfico 4. ASEAN: 10 principais fontes de IED}

$(\mathrm{em} \%)$

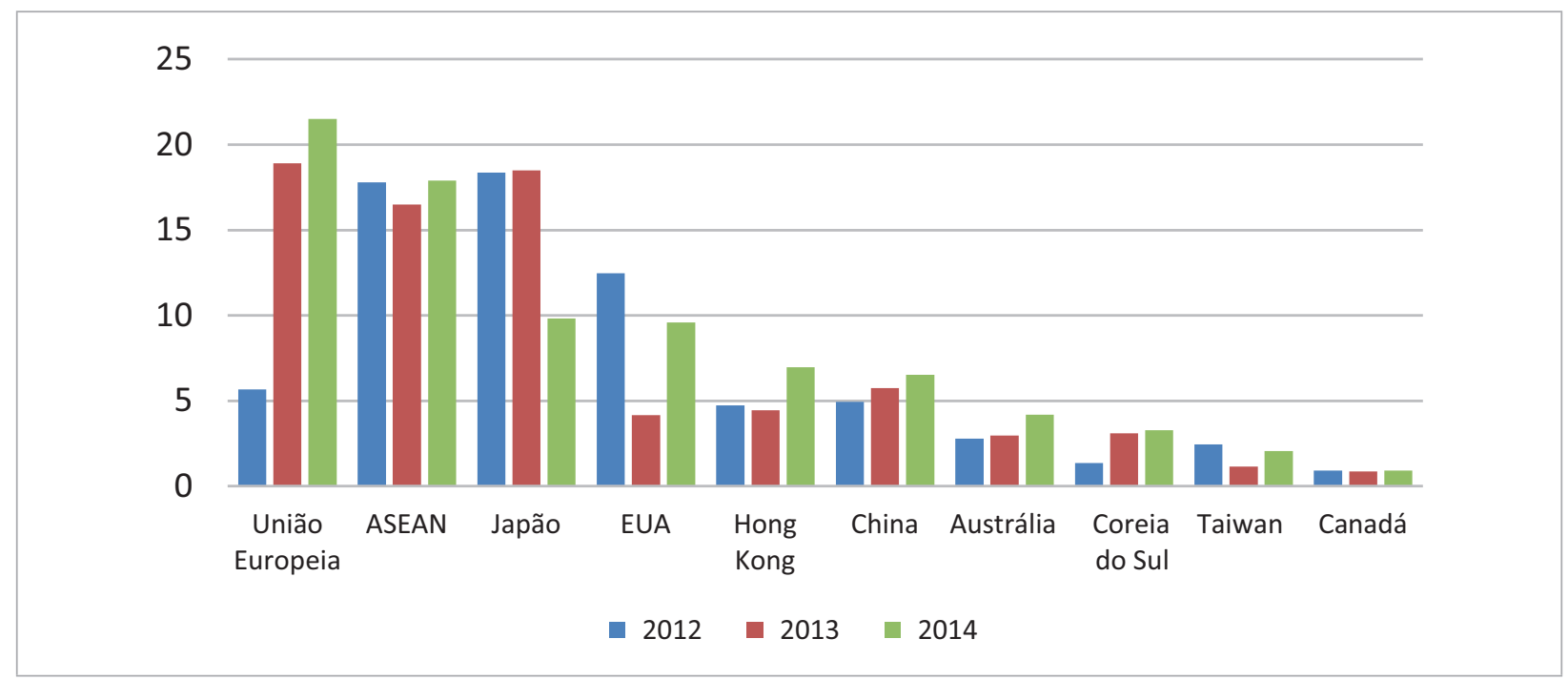

Fonte: ASEAN, 2016.

6 Thriftiness on the part of Western consumers has led to a collapse of the appetite for goods made from components and raw materials from Asian, African and Latin American countries and assembled in China. Facing this changing world order, it is necessary for China and ASEAN to revise their role in the global economy in order to ensure a continuation of their economic development. (MU, SIAM-HENG, 2011, p. 132) 
A China tornou-se o principal parceiro comercial de boa parte dos países do mundo. O mesmo ocorreu com as nações da ASEAN. A diferença é que o avanço comercial e financeiro chinês no SE Asiático é escorado em um economic statecraft que abrange a atuação de bancos estatais, empresas estatais, política externa ativa e uma política de segurança e defesa com crescente aporte financeiro e tecnológico (REILLY, 2011).

A ocupação de espaços estratégicos também se dá pela diplomacia, movida pelo temor de surgimento de uma aliança antichinesa liderada pelos EUA (LI, 2009, p. 18). Visitas de políticos, diplomatas de alto escalão, militares e acadêmicos ao SE Asiático são cada vez mais frequentes, geralmente reiterando o discurso da boa vizinhança e da construção de um ambiente de confiança mútua, tão prezado pelos membros da ASEAN. Ademais, no âmbito multilateral, a China foi o primeiro país a criar uma representação permanente para essa organização.

No entanto, a retórica da boa vizinhança e da cooperação bi e multilateral choca-se com a postura chinesa no tocante aos litígios territoriais envolvendo Filipinas, Vietnã, Brunei, Malásia e Taiwan no Mar do Sul da China. A percepção da China como uma ameaça por esses países é fortalecida pelo contexto de modernização das forças armadas, pela atuação belicosa da marinha chinesa ao lidar com barcos pesqueiros estrangeiros em áreas em disputa e pela construção de bases militares e povoamentos civis em ilhotas na região.

Os investimentos militares da China, embora estejam crescendo no mesmo ritmo de expansão da economia e representem hoje cerca de $2 \%$ do PIB, agravam a percepção de ameaça na região, principalmente pelas altas cifras em valores absolutos. Ademais, criam a sensação de que, mais cedo ou mais tarde, a periferia econômica da China tornar-se-á também uma periferia geopolítica em que os EUA terão gradualmente menos influência.

Ao longo dos últimos anos, tem se tornado claro que a China leva adiante um projeto que busca combinar uma política de boa vizinhança com a ASEAN a uma política agressiva de controle de recifes e ilhotas que contêm reservas de recursos minerais e estão estrategicamente localizados entre as principais rotas navais do mundo. Há, evidentemente, uma tensão latente entre essas duas políticas contraditórias do ponto de vista da periferia do sistema. A postura unilateral sobre o impasse que persiste há décadas, bem como a percepção de ameaça entre as elites dos países menores (principalmente Filipinas e Vietnã) e a consequente aproximação desses entre si (ao preferir negociar em bloco) e 
com os EUA, evidenciam que o "arquipélago de economias de mercado" da Ásia Oriental, onde a riqueza vem antes do poder, está longe de se tornar realidade.

Portanto, apesar da atuação diplomática da China e do discurso de "boa vizinhança”, o terceiro ciclo de relações com o SE Asiático torna mais nítido o processo de construção de uma periferia chinesa por meio das esferas comercial, financeira e político-militar. Com o "retorno" dos EUA à Ásia, por meio do pivô estratégico do governo Obama e a possível continuidade da política de cercamento da China por parte da nova administração Trump, talvez de forma ainda mais agressiva, esse processo tende a enfrentar desafios em todas as áreas e tornar-se um projeto gradual e de longo prazo.

\section{Conclusões}

A hipótese de Arrighi sobre a possível formação de um "arquipélago de economias de mercado" na Ásia Oriental resiste até o ponto em que as demais nações da região não percebam o avanço chinês como ameaça a sua autonomia e a seus interesses nacionais, e confiem na centralização das capacidades militares globais "nas mãos dos EUA". Porém, ambos os processos não parecem nítidos e muitos dos países do SE Asiático tendem a rumar para um caminho intermediário, em que obtêm cada vez menos retornos econômicos e geopolíticos com a ascensão chinesa e não reconhecem ou tampouco confiam apenas na supremacia militar norte-americana para lidar com a China.

A tendência da relação China-SE Asiático após 2008 nunca esteve tão longe da seguinte afirmação de Arrighi e Silver: "Uma vez que as economias da Ásia Oriental devem suas fortunas a uma rigorosa especialização na busca da riqueza, e não do poder, não se pode esperar que nenhum deles (...) venha a mudar de rumo, tentando transformar-se em uma potência militar de importância mais do que local" (ARRIGHI; SILVER, 2001, p. 288). A projeção chinesa sobre a Ásia Oriental (e especificamente sobre o SE Asiático) dá sinais claros de que o país tem buscado se transformar em uma potência regional em todos os sentidos, inclusive militar, ainda que escorada em pilares econômicos cada vez mais assimétricos em relação a seus vizinhos.

A partir disso, duas tendências podem ser depreendidas do terceiro ciclo pós-Guerra Fria: 
1) O "retorno" multifacetado dos EUA à Ásia com o redirecionamento gradual do aparato militar e diplomático por meio do "pivô estratégico". Enquanto o governo W. Bush esteve mais focado no Oriente Médio com a Guerra ao Terror nos anos 2000, o governo Obama parece muito mais atento à Ásia Oriental, reduzindo a margem de manobra da China com uma diplomacia ativa e uma crescente projeção militar que vai da Austrália ao Japão, passando por Indonésia, Cingapura, Tailândia, Filipinas e Taiwan. Ademais, os mega-acordos regionais, como a Parceria Transpacífico, e os vários acordos bilaterais já existentes dão mostras de que a atuação dos EUA vai muito além da esfera militar. O TPP, por exemplo, é um acordo explicitamente feito para tentar conter a expansão chinesa na Ásia e para forjar um novo regime internacional de comércio e investimento sob a égide norte-americana.

2) A formação de uma periferia econômica chinesa a partir da transição do modelo de desenvolvimento voltado para o investimento interno e as exportações para a expansão do mercado de consumo e de mercados regionais. O modelo que vigorou até os anos 2000, em que a China funcionava como um "duplo polo", tem dado sinais de exaustão, sendo gradualmente substituído por políticas que elevam os salários dos trabalhadores e estimulam a demanda doméstica e regional. Muitas empresas do SE Asiático têm sofrido com essa mudança, pois não conseguem concorrer com empresas chinesas e ocidentais. O déficit comercial da China com o SE Asiático era um forte argumento para a criação da área de livre-comércio China-ASEAN, mas os números pós-crise de 2008 mostram que os países do bloco se tornaram altamente deficitários no comércio com o gigante asiático e suas exportações foram reprimarizadas, principalmente após a entrada em vigor do CAFTA em 2010.

Como consequência dos pontos 1 e 2, o SE Asiático tende a se tornar um palco de grande relevância no jogo por poder e riqueza entre EUA e China e se afastar do cenário proposto por Arrighi de formação de um "arquipélago de economias de mercado”. Do ponto de vista chinês, o ganho máximo seria a gradual formação de uma periferia geopolítica acoplada a uma periferia econômica mais consolidada. Do ponto de vista norte-americano, o ganho máximo seria evitar a gravitação econômica do SE Asiático em torno da China e, se isso não for possível, evitar que essa periferia se transforme, também, em uma periferia geopolítica, o que 
minaria posições estratégicas dos EUA na Ásia, construídas desde antes da Guerra Fria. Entre esses dois polos de ganhos máximos, há uma ampla “zona cinzenta” em que os fatos ocorrem e tendem a ser moldados pelas conjunturas e estruturas de mais longa duração.

\section{Referências Bibliográficas}

ABU-LUGHOD, Janet. Before European hegemony: The world system AD 1250-1350. Oxford: Oxford University Press, 1989.

ACHARYA, Amitav. Asia Rising: who is leading? Singapura: World Scientific Publishing Co, 2008.

AGLIETTA, Michel; BAI, Guo. China's Development: Capitalism and empire. Londres e Nova York: Routledge. 2013.

ARRIGHI, Giovanni. Adam Smith em Pequim: origens e fundamentos do século XXI. São Paulo: Boitempo. 2008.

ARRIGHI, Giovanni; SILVER, Beverly J. Caos e governabilidade no moderno sistema mundial. Rio de Janeiro: Contraponto: Editora UFRJ. 2011

ARRIGHI, Giovanni; SILVER, Beverly J. 2011. The End of the Long Twenieth Century. In: Business as usual: the roots of the global financial meltdown. New York: New York University Press. 2011.

ASEAN. Site oficial da ASEAN. Disponível em: http://asean.org/. Acesso em 14/08/2016.

BATSON, A. Can the New Silk Road Revive China's Exports? Gavekal Dragonomics, China Research. 2015.

CARNEIRO, Flavio. A Parceria Transpacífica: Principais características e impactos sobre a regulação do comércio mundial. Boletim de Economia e Política Internacional, no 18. Set./dez. 2014.

DIAMOND, Jared. Armas, germes e aço: os destinos das sociedades humanas. Rio de Janeiro, Editora Record, $8^{\text {a }}$ ed. 2006.

FRANK, Andre G.. ReOrient: global economy in the Asian Age. Los Angeles, CA: University of California Press. 1998.

GEORGE, Suzan. Shadow Sovereigns: How global corporations are seizing power. Londres: Polity. 2015.

KAPLAN, Robert. Asia's cauldron: The South China Sea and the end of a stable Pacific. Nova York: Random House, 2014.

KHAN, Raja Muhammad. Sino-U.S. rivalry in Southeast Asia. Turkish Policy Quarterly. Vol. 11, nº 3, 2012. Disponível em: http://turkishpolicy.com/Files/ArticlePDF/sinou-s-rivalry-in-southeast-asia-fall-2012-en.pdf. Acesso em 12/05/2016. 
KISSINGER, Henry. Sobre a China. Rio de Janeiro: Objetiva. 2011.

LI, Mingjiang. Explaining China's proactive engagement in Asia. In: TANG, Shiping, LI, Mingjiang; ACHARYA, Amitav (orgs.). Living with China: regional states and China through crises and turning points. Nova York: Palgrave Macmillan. 2009.

MAJID, Munir. Southeast Asia Between China and the United States. London School of Economics and Political Science. 2013.

MEDEIROS, C. Desenvolvimento econômico e ascensão nacional: rupturas e transições na Rússia e China. In: MEDEIROS, C; FIORI, José L.; SERRANO, Franklin. O mito do colapso do poder americano. Rio de Janeiro: Record. 2008.

MILLER, Tom. Junho. Asia’s Infrastructure Arms Race. Gavekal Dragonomics, China Research. 2015.

MU, Yang; SIAM-HENG, Heng. China-ASEAN Relations after CAFTA. In: LI, Mingjiang; KWA, Chong Guan (orgs.). China-Asean sub-regional cooperation: Progress, Problems and Prospect. Singapura: World Scientific Publishing Co. 2011.

NATHAN, Andrew J.; SCOBELL, Andrew. China's search for security. Nova York: Columbia University Press. 2012.

NOGUEIRA, Isabela. A Política Regional da China e os Processos de Integração na Ásia. In: China - Conferência Nacional de Política Externa e Política Internacional. Brasília: Fundação Alexandre Gusmão. 2008.

NOGUEIRA, Isabela. Políticas de Fomento à Ascensão da China nas Cadeias Globais de Valor. In: CINTRA, Marcos Antonio; SILVA FILHO, Edison; PINTO, Eduardo. China em transformação. Brasília: IPEA. 2015.

REILLY, James. China's economic statecraft: turning wealth into power. Sidney: Lowy Institute For International Policy. 2011.

SØRENSEN, Camilla. The Significance of Xi Jinping's "Chinese Dream” for Chinese Foreign Policy: From "tao guang yang hui" to "feng fa you wei”. Journal of China and International Relations. vol. 3, n $1,2015$.

SPENCE, Jonathan. Em Busca da China Moderna. São Paulo: Companhia das Letras. 2000

STUART-FOX, Martin. A short history of China and Southeast Asia: tribute, trade and influence. Maryborough, Austrália: Allen \& Unwin, 2003.

UNITED STATES TRADE REPRESENTATIVE. The Trans-Pacific Partnership: Overall U.S. benefits. United States Trade Representative, Washington D.C. 2015. Disponível em: https://ustr.gov/sites/default/files/TPP-Overall-US-Benefits-Fact-Sheet.pdf. Acesso em 09/02/2016. 